\title{
La hospitalidad de la marginada, la casa de Rahab
}

\author{
Rosa Estela Yánez Poblete* \\ Pontificia Universidad Católica de Chile \\ rosaeyp@gmail.com \\ Recibido 20.11.2020/ Aprobado 25.04.2021 \\ DOI: https://doi.org/10.46553/teo.58.135.2021.p79-91
}

\section{RESUMEN}

La cuestión del extranjero es un tema que atraviesa la Escritura y con ello la cuestión de la acogida del migrante es un gesto que muestra una acción del Dios Santo y Justo, su Hesed.

En este trabajo reflexionamos a partir del relato de Jos 2,1-24 y desde la figura de Rahab el cómo la hospitalidad de la marginada abre un espacio de humanidad donde se hace efectiva la praxis humanizadora desde el don gratuito.

Palabras clave: Acogida; No reciprocidad; hospitalidad; Praxis humanizadora

The Hospitality of the Marginalized, the House of Rahab

\section{ABSTRACT}

The theme of the foreigner appears throughout the Scripture and with that the question, the reception of the migrant is a gesture that shows the action of the Holy and Righteous God, his Hesed.

In this work, we reflecto $n$ story in Joshua 2,1-24 and on the figure of Rahab: How the hospitality of the marginalized opens a space of humanity where humanizing practice become effective from the divine gift.

Key words: Welcome; Non-reciprocity; Hospitality; Humanizing praxis

- La autora es Magister en Teología Bíblica por el Institut Catholique de Paris. Enseña, desde 2019 , en la Pontificia Universidad Católica de Chile. Dicta el curso de Libros Sapienciales y Nuevo Testamento (I-II) en el Programa Interfacultades de Pedagogía en Religión Católica. 
En tiempos que las noticias nos traen las imágenes de migrantes cruzando el mar en pateras, llegando desfallecientes a tierras donde, no siempre son bien recibidos. En nuestros continentes hombres, mujeres, niños, ancianos parten de su tierra hacia inseguros destinos; tierras nuevas que, al igual que en otros continentes, no siempre acogerán al migrante, al huésped de otras tierras.

Al hablar de migrantes, desde una mirada Bíblica, se puede caer en una cierta espiritualización del hecho de migrar: romper con la tierra y salir, partir por un llamado del Señor, ahí está el ejemplo de Abraham: «marchó pues Abraham como se lo había dicho Yavé» (Gn 12,4) Sin embargo, partir, romper con la tierra y las tradiciones crea un espacio de vacío, no es una aventura romántica; es un riesgo, es verse enfrentado a las dificultades de ser «el otro», el extranjero, es enfrentarse a prejuicios, los propios y los ajenos. Así, Ruth la migrante, será llamada siempre «la moabita» subrayando, con esta nominación, su origen extranjero, su otredad, su «no eres de los nuestros» (Rt 1,$22 ; 2,2.6 ; 4,5)$

Salir de la tierra, migrar conlleva peligros y desamparo que marcan la vida y la historia del migrante, tal vez por ello, una vez asentado el migrante puede repetir las actitudes de desconfianza hacia el otro, o bien, marcado por el rigor del salir hacerse, él o ella misma un huésped para un otro.

Abraham que conoce, en su carne, el rigor de las jornadas por el desierto y los caminos acoge, bajo su tienda, a los caminantes en mambré, a la hora más calurosa del día, subraya el texto (Gn 18,1-5) Si, el patriarca y su familia saben que, en el desierto, la hospitalidad hace la diferencia entre la muerte y la vida del caminante; así lo señala el Derecho Consuetudinario de las tribus del desierto; abrir la tienda al otro es un deber sagrado que no depende de una buena voluntad, es un acto que iguala al «hospedado y al que hospeda». 1 Como lo muestra Abraham acoger no es solo dar comida, agua y

1 Cf. Carlos Gil A, dir., Reseña Bíblica, El inmigrante en la Biblia (Estella: Verbo Divino, 2005), 10-12. 
abrigo, es abrir un espacio de humanidad, de escucha, de acompañar; la acogida es, en definitiva, un espacio de riesgo y desinstalación (Gn 18,6-13)

Pero hoy, en el escenario de las migraciones modernas y de los Estados modernos ¿cómo pensar la hospitalidad? ¿qué luces nos pueden entregar los hombres y las mujeres bíblicas que vivieron, ya sea la partida, ya sea la acogida? Estas son las preguntas que motivan esta reflexión. Para esbozar alguna respuesta, pertinente para hoy, hemos elegido conocer, escuchar y contemplar a Rahab, la mujer de Jericó que oculta a los espías de Josué (Jos 2.6). La mirada con la cual nos acercaremos a ella será, reconociendo en Rahab, a las mujeres marginadas de nuestras grandes y populosas ciudades; aquellas mujeres que se instalan en una esquina, buscando un espacio de trabajo, aquellas que con un pequeño comercio callejero buscan conseguir «algo de dinero» para la familia; mujeres cuyo comercio se trasforma, a veces, en un espacio de encuentro, de un rápido saludo que rompe el anonimato de los «urgidos» empleados, obreros de cualquier ciudad.

¿Por qué nos detenemos en Rahab y no una de las matriarcas? Esta mujer es citada en dos oportunidades en textos del Nuevo Testamento como ejemplo de fe. En hebreos, Rahab es nombrada en la lista de los creyentes que muestran, con sus hechos, lo que es la fe: «Por la fe, Rahab la prostituta, no pereció con los rebeldes, pues ella había acogido pacíficamente a los espías» (Hb 11,31)

En la carta de Santiago, la misma acción que estudiamos: acoger a los espías, es descrita como un ejemplo de fe viva: Lo mismo pasó con Rahab, la prostituta, ¿no hizo méritos con las obras, alojando a los mensajeros y haciéndolos salir por otro camino (St 2,25) ¿qué hace de Rahab un modelo de fe en la larga lista de los antepasados? ¿Qué hace que la acción de esta mujer extranjera sea citada como modelo de fe? Tal vez ahondando en su hospitalidad podamos también encontrar una respuesta a esta pregunta. 
¿Qué decir de Rahab y la hospitalidad? La respuesta a esta pregunta la trabajaremos en tres momentos: Primero, nos acercaremos a la Rahab, la mujer de Jericó ¿quién es? ¿qué hace? ¿dónde vive?, en un segundo momento nos detendremos a analizar la acogida que, Rahab, da a los espías, nos preguntamos ¿sentido tiene ese acto en ese preciso momento de la historia de la «ocupación de la tierra»? Y finalmente, desde ese acto de hospitalidad dirigiremos, nuestra mirada, a los gestos de hospitalidad de hoy.

\section{Rahab, la mujer de Jericó}

Según los datos que nos entrega Jos 2,1- 21, Rahab es una cananea, prostituta en Jericó (v.1c) vive dentro de la ciudad, su casa está pegada a la muralla (v.15) de tal modo que, en caso de ataque, era la primera en caer. Lo anterior da a entender que Rahab vivía en un barrio marginado de la ciudad, alejado del centro y de las seguridades que, en esa época, daba vivir junto a la corte. Por el oficio que ejerce, tal vez era objeto de desprecio o, al menos, de comentarios, de miradas indiscretas de los vecinos, el texto señala que le avisan al rey diciendo: «Se le dijo al rey de Jericó: 'Mira, unos hombres israelitas han entrado aquí por la noche para explorar el país"». Entonces el rey de Jericó hizo llamar a Rahab [...] (v.2-3a)

Seguramente, los exploradores, no eran los primeros hombres que entraban en casa de Rahab y pasaban la noche allí; lo que inquieta a los vigías es que sean israelitas, los enemigos que amenazaban la ciudad por ello van y avisan al rey.

El mismo texto deja ver que Rahab es una mujer lúcida, de acción: esconde a los espías y cuando los soldados vienen a su casa, para requerir información usa, astutamente, la imagen que los soldados tienen de mujeres como ella: en ningún caso niega haber recibido a los espías, pero, afirma haberlo hecho «sin saber de quienes se trataba». Agrega, además: ellos partieron al anochecer, antes que la puerta de la ciudad se cerrara, por lo tanto, ella no sabe de su pa- 
radero. Además, se preocupa de dar algunas indicaciones de tiempo, de tal modo, que los perseguidores puedan dar alcance, a los supuestos fugitivos: «Cuando se iba a cerrar la puerta por la noche, esos hombres salieron y no sé adónde han ido. Perseguidlos aprisa, que los alcanzaréis» (v.5)

La elección de ruta, que hacen los soldados, responde a la lógica propia de su experiencia en la guerra: si son fugitivos israelitas seguro que intentarán cruzar el Jordán para entrar en su campamento: «Salieron algunos hombres en su persecución camino del Jordán, hacia los vados» (v.7)

En el diálogo con los enviados de Josué el texto muestra otro aspecto de esta mujer, una fina intuición que le ha permitido discernir, en la historia que se cuenta de ese pueblo que acampa al otro lado del río, la mano de Yavéh. De hecho, al abrir el diálogo dice: «Yo sé ${ }^{2}$ que Yavéh os ha dado esta tierra» (v.9 a) mostrando, de esta manera que su acción no ha sido el fruto de un puro impulso momentáneo, sino que tiene una raíz más profunda: el reconocer, en la historia de la reciente liberación de ese pueblo, cuyos hitos ella narra, la poderosa mano de Yavéh, «es Dios arriba en los cielos y abajo en la tierra» (v.9-10). Sólo después de hacer esta declaración, demanda que los enviados de Josué, juren proteger del exterminio la casa de su padre y su clan al momento que Yavéh entregue, en manos de Israel, a la ciudad; además ella sabe, por la situación marginal de su vivienda, que en un ataque los primeros en perecer son los defensores de la muralla y los que viven ahí. Es el pedido de Rahab lo que muestra la intuición de esta mujer: no se trata de un simple intercambio de protección por protección, un cierto «comercio de acciones recíprocas», lo que ella pide tiene unas bases mucho más profundas: «Juradme, pues, ahora por Yavéh, que, ya que os he

2 Cf. Xavier Léon-Dufour, Dictionnaire du Nouveau Testament (París: Du Seuil, 1996) 181. En la Biblia conocer no se reduce al acto de la inteligencia que toma el objeto. El concepto conserva la dimensión experimental que la caracteriza: discernir, establecer una relación íntima entre dos personas. El conocimiento de Dios es posible, porque es un reconocer a Aquel por su creación que está ahí. Conocer es estar dispuesto a obedecer. Traducción propia. 
tratado con bondad, ${ }^{3}$ también vosotros tratareis con bondad a toda mi familia».(v.12)

De esta manera, lo que está en juego es la actitud que va a inspirar la acción, una actitud que se enraíza en un atributo propio de Yavéh y que su pueblo conoce, pues lo ha experimentado en su travesía por el desierto y en el gesto liberador de la esclavitud; es el Hesed del Señor Dios que los ha sacado de la tierra de Egipto, el país de la esclavitud y los ha traído hasta aquí. Entonces, a partir del texto, podemos afirmar que Rahab ha sido capaz de discernir, en la gesta liberadora que se cuenta, el Hesed del Señor Dios que ella reclama como la razón fundante del pacto que propone a los espías.

Los enviados de Josué aceptan el pacto, sobre las bases propuestas por Rahab, entregan la prenda que sella el acuerdo: una cuerda escarlata que deberá pender de la ventana, por donde ellos han escapado y se han puesto a salvo. Todo concluye cuando Rahab descuelga, a los fugitivos, por la ventana de su casa y como último signo de su compromiso, hacia ellos, les indica seguir el camino de las montañas, donde deben permanecer tres días, el tiempo prudente para escapar de los perseguidores.

\section{La acción de Rahab}

Sin duda la acción de Rahab hacia los espías hace de ella un personaje controvertido: el texto señala que hospeda los espías enviados por Josué, recordemos que estos espías eran los encargados de conocer las defensas de la ciudad y detectar las debilidades para

3 Cf. Biblia de Jerusalén (Bilbao: Desclée de Brouwer, 1998) La Biblia de Jerusalén traduce por bondad el hebreo hesed (חס) Nos parece importante subrayar que hesed ( es un atributo propio del Señor Dios, en Ex 34,6 el Señor Dios pasa delante de Moisés y proclama: «El Señor, el Señor, el Dios compasivo y clemente, paciente, rico en bondad (hesed) y fidelidad, guardando su bondad (hesed Tợ) hasta la milésima generación» (Ex 34,6-7) En esta proclamación, al no haber un sujeto expresado, se entiende que es el Señor Dios que se presenta a si mismo y revela su nombre y sus atributos dentro de los cuales encontramos dos veces el hesed (סָס). Hesed, en la tradición judía y en cuanto atributo de Divino expresa todo lo gratuito y bueno. Lo interesante es que el texto de Jos 2,12 muestra que Rahab, la cananea, es capaz de actuar con Hesed y pedir a los espías que actúen de igual manera hacia la casa de su Padre. 
así planear el ataque por lo tanto, esos dos hombres son enemigos de Rahab, de su clan y de su ciudad. Sin embargo, ella los hospeda, los esconde, les da tiempo para escapar y los descuelga por la muralla. El texto subraya que Rahab, ante los espías, declara «saber» que el Señor Dios de Israel ha entregado la ciudad en sus manos. Ese «saber» de Rahab, no es un mero conocer una información, va mucho más allá de un conocimiento cognitivo. Se trata de ser capaz de discernir el significado, el sentido de aquellos hechos «conocidos» a través de la mera información. Por lo tanto, Rahab es capaz de «discernir», en las sucesivas derrotas de las derrotas de los reyes que se han opuesto al paso de Israel, la acción del Señor. En esas acciones, según lo que expresa Rahab, el Dios de Israel ha mostrado su poder, un tal poder que toda la ciudad tiembla y el corazón de sus habitantes se funda en el horror. ${ }^{4}$

Sin embargo, ella, al parecer, pese al temor que la invade, como a toda su ciudad, ha descubierto algo más. ¿Qué puede ser ese algo más? Ese algo que la impulsa a declarar aquello que dice conocer del Dios de Israel y que se convierte en la base del pacto de resguardar la vida de la casa de su padre y su clan.

En este punto es necesario subrayar que, en el mundo bíblico, conocer predispone a obedecer pues implica ya, una experiencia de aquel que es conocido; también conviene subrayar que en la declaración de Rahab, ante los espías es posible encontrar elementos deuteronomistas: en v.10b.11, por su vocabulario en v.9b tiene ecos de Ex 15,15.16. ${ }^{5}$ Volviendo al pedido de Rahab, es necesario destacar que en ningún momento pide una protección para ella misma, lo central del pedido es guardar del exterminio la casa de su padre, su familia y su clan. Es quizás, a partir del contenido, del pedido de Rahab, que ella en su argumento va a invocar la bondad (hesed)

4 Cf. Jos 2,8-11.

5 «Se espantaron los jefes de Edom, un temblor sacude a los príncipes de Moab, perdieron el valor todos los jefes cananeos; los asaltaron tu espanto y tu pavor, los dejó petrificados la grandeza de tu brazo, mientras pasaba tu pueblo, Señor, mientras pasaba el pueblo que te habías comprado» (Ex 15,15-16). 
como el contenido central de su acción. De ahí que sea una acción que no implica un intercambio recíproco, no origina una obligación, es una acción gratuita basada en la bondad de Dios hacia su pueblo, un don que solo tiene sentido, a su vez, en un darse. Por esto ella puede pedir aquello que va más allá de cualquier posibilidad mercantilista: la bondad sólo puede ser deudora de más bondad, la hospitalidad sólo se responde con hospitalidad, salvando a su vez la vida de otro. De tal manera, su acción bondadosa (hesed) gratuita, compromete, a los espías y a su pueblo, en la misma dirección de bondad (hesed) hacia la casa de su padre y su clan, no hacia ella en especial ni, en primer lugar.

El día del ataque, Josué manda a los mismos hombres que hicieron de espías, aquellos que Rahab había hospedado, a hacerla salir de la ciudad, junto a toda su familia para llevarlos a un lugar seguro, fuera del campamento de Israel. ${ }^{6}$ El texto finaliza afirmando que Rahab y su familia permanecen ${ }^{7}$ en Israel por haber dado hospedaje a los exploradores enviados por Josué.

\section{¿Una traidora?}

Esta sucesión de acciones ¿qué hacen de ella? ¿Una traidora que entrega su ciudad? ¿Una mujer decidida que, desde su posición marginal, logra salvar la casa de su Padre y su clan (Jos 6,23) y da la posibilidad de que se cumpla la voluntad del Señor? ¿Una manipuladora que mueve magistralmente los hilos de situación logrando que se ordenen según sus deseos?

Discernir aquello que muestra la acción de Rahab no es sencillo, dado lo complejo de esta mujer.

6 No podían entrar al campamento pues al ser extranjeros lo volverían impuro y esto alejaría a Yavéh de allí (Dt 23,1 5-16).

7 Quizá por ello el redactor de evangelio según san Mateo, en la genealogía del Mesías, menciona a una Rahab, como antepasada del Mesías. No nos en probar si esta Rahab es la misma cananea de Jericó. 
Lo primero que podemos afirmar es, ante todo, que su acción, en los cánones de su cultura y del mundo bíblico, es una acción de hospitalidad, obedece las leyes ancestrales de los pueblos del desierto, ofrece al extraño su casa y su protección, crea así un espacio de compartir que humaniza, que rompe barreras, que compromete. En ese espacio de hospitalidad el migrante, el extranjero (los exploradores israelitas) dejan de ser los enemigos y pueden experimentar el don gratuito de ser huésped, no como un derecho adquirido sino como pura gratuidad del que hospeda, ${ }^{8}$ experimentan así que la hospitalidad humaniza, que da un rostro a ese otro, el enemigo, el desconocido; esto tanto para el que acoge como para el huésped. Los espías saben que lo recibido es un don gratuito que, a la vez, les compromete a actuar de la misma manera; no se trata de una reciprocidad mercantil, sino de un acto de acogida y reciprocidad de marginados, de caminantes, de pobres. Los israelitas hospedaran a Rahab, su familia y su clan, en un lugar seguro: fuera del campamento, para así guardar la pureza y asegurar la presencia de Yavéh y lanzaran el ataque en el que perece la ciudad. La Casa del Padre de Rahab, su Clan y ella misma vivirán en medio de Israel hasta el fin de sus días. (Jos 6, 25)

Es una traidora, al parecer no. Según el texto Rahab sabe muy bien, los habitantes de Jericó también, de las obras de Yavéh; nadie ha podido vencer a ese pueblo de hecho, ella misma lo reconoce ante los espías: todos los hechos han mostrado que rebelarse ante Yavéh es tener todo perdido. Quizá, la diferencia fundamental entre Rahab y los suyos sea que ella ha podido discernir, en los hechos relatados de Yavéh con su pueblo, la presencia del Señor Dios y de esta manera, no solo está informada de los hechos de Yavéh, como lo ha hecho el Rey, que teme ese poder como se teme a un enemigo que se sabe poderoso, sino que Rahab conoce experimentalmente

8 El gesto de hospitalidad de Rahab se presenta como un eco de aquel ofrecido por Abimelec hacia Abraham pues, pese a que en el caso de Abimelec todo comenzó por el miedo de Abraham hacia el extranjero, una vez experimentada la hospitalidad y eliminadas las desconfianzas todo termina en un juramento que tiene como base la la reciprocidad de benevolencia de Abraham hacia la casa de Abimelec por siempre (Gn 21,23-24). 
al Señor Dios, de ahí que obedezca y vea claro que la rebelión es la muerte y actuar con hospitalidad (hesed) crea un espacio gratuito de encuentro y conocimiento mutuo que posibilita la vida.

De lo anterior, podemos concluir que esta mujer no es una traidora a su pueblo ni una manipuladora. Es más bien una mujer marginal que usando su fina intuición logra discernir, más allá de las apariencias de ese pueblo y de los hombres que ella hospeda en su casa, el poder del Señor y una familiaridad de marginales que la acerca a los Israelitas. Es una mujer de una fina percepción de los hechos y de las personas por ello, logra percibir la presencia creadora, liberadora y gratuita del Señor Dios de tal manera, que su gesto de hospitalidad será un eslabón que permitirá llevar a cabo la gesta liberadora de Yavéh para con su pueblo, gesta que alcanza también el clan de Rahab que es el único que escapa al anatema lanzado contra la ciudad de Jericó. Hospedar es pues la diferencia entre la vida y la muerte.

\section{Rahab hoy en las esquinas de nuestras calles, en nuestros barrios marginales}

Ante la llegada de migrantes los gobiernos y las instituciones humanitarias crean espacios de acogida para ellos. Sin embargo, esos espacios, fruto de tanto esfuerzo, no siempre llegan a aquellos que los necesitan, en contraste, muchos migrantes y excluidos llegan a los barrios y allí se asientan, logran encontrar un espacio de pertenencia ¿qué sucede?

Tal vez Rahab nos entregue una clave: en su gesto la hospitalidad no es pura buena voluntad, es una acción que toma en cuenta a aquel a quien se le ofrece la hospitalidad, el que hospeda se detiene en el huésped pues, de alguna manera, se intuye que acogerle es salvarle la vida; no porque vaya a morir en el desierto, en el mar, al cruzar el río, solamente, sino porque algo de su humanidad se pierde en el desarraigo de la partida. 
La hospitalidad, al crear un espacio de gratuidad, debería ser entendida como un don $y$, por lo tanto, es una llamada al contra don ${ }^{9}$ es decir, esa deuda de gratuidad que nos humaniza y hace que, ambos, tanto el que hospeda como el huésped, vayan más allá de la apariencia encontrándose en la fragilidad de aquel que sabe que necesita de los demás. Por ello y después de conocer a Rahab, nos parece, que la hospitalidad, entendida desde la Biblia, es aquel «urgente momento» en que el acto de abrir o no la puerta significa la diferencia entre la vida y la muerte, entre el riesgo solidario y la seguridad indiferente.

Y hoy, cuando las organizaciones humanitarias no dan abasto a las demandas de los desplazados, cuando los gobiernos prefieren cerrar sus fronteras olvidando que, en algún momento, nuestros antepasados partieron y fueron hospedados por otros pueblos; los espías, Israel, nos recuerdan que cada uno guarda una deuda de hospitalidad, que todos hemos sido, en algún momento, salvados de la deshumanización por alguien que no preguntó ni dio razones, simplemente abrió ese frágil espacio de humanidad que hace la diferencia entre la vida y la muerte.

Al preguntarnos ¿por qué esa mujer, extranjera, comerciante ilegal vende café en una esquina? ¿por qué sigue ahí, enfrentado las dificultades? Quizá, debiéramos mirar más de cerca lo que pasa en ese espacio: al mirar veríamos que los que compran no son los grandes, ni los importantes, son obreros, estudiantes, trabajadores, personas frágiles, sin poder, fácil presa del poder político, policial, criminal. Compran, al pasar, algo que satisface una necesidad y, a la vez, hay siempre un momento para una sonrisa, un comentario del tiempo, un momento para detener la prisa y finalmente un momento de humanidad. ${ }^{10}$ Lo terrible es que existen sistemas que pervierten

9 Cf. Jean-Daniel Causse, El don del agapé, constitución del sujeto ético (Santander: Sal Terrae, 2006), 46-50.

10 Tony Mifsud, Una espiritualidad desde la fragilidad (Santiago: Edic. Revista Mensaje, 2014), 59.

«Esta necesidad de reconocimiento manifiesta la fragilidad humana. La necesidad de ser reconocido por otro que, a su vez, sea reconocido por uno mismo, supone la posibilidad de ser 
ese espacio y explotan a los débiles instalándolos en esquinas como un mero objeto de negocio.

¿Por qué nuestras organizaciones fallan? Quizá porque en lugar de ser centros de hospitalidad son centros de administración de recién llegados, altamente especializados que saben lo que hay que hacer de manera eficiente y eficaz, manejados con criterios de jerarquización que es la negación misma de la gratuidad y del espacio de humanidad. Tal vez, en esos centros, el recién llegado es sólo uno más en la lista y otro problema a resolver. En un esquema, puramente organizacional, el recién llegado, el extranjero no un huésped a quien atender, de quien aprender y con quien humanizarse haciendo juntos una parte del camino, en ese esquema nos quedamos, otra vez, manejando el miedo de la ciudad a los extranjeros que acampan bajo sus murallas, olvidando que, tal vez, al darnos un espacio de hospitalidad podemos evitar a catástrofe al descubrir que, en la incertidumbre de la acogida, se juega, una vez más, la vida o la muerte.

\section{Bibliografía}

Alonso Schökel, Luis, Diccionario Bíblico Hebreo- español. Edic. preparada por Víctor Morla y Vicente Collado. Madrid: Trotta, 2008.

Causse, Jean-Daniel, El don del agape, constitución del sujeto ético. Santander: Sal Terrae, 2006.

Léon-Dufour, Xavier, Dictionnaire du Nouveau Testament. Paris: Du Seuil, 1996.

Fischer, Irmtraud, Des femmes aux prises avec Dieu. Récits bibliques sur les débits d'Israël. Paris, Du Cerf, 2008.

\footnotetext{
herido, al ser negado ese reconocimiento. En este caso, la fragilidad deja de ser posibilidad y se transforma en realidad amenazante para quien la vive. Por consiguiente, en cuanto conciencia de que los demás comparten la misma fragilidad y dignidad, el reconocimiento se relaciona con la solidaridad y con compasión. Desde esta perspectiva, el reconocimiento se hace condición de posibilidad para la reconciliación, ya que implica la afirmación del otros frágil en su radicalidad otreidad y, a la vez, en su inviolable derecho a una vida conforme a su dignidad».
} 
Gil, Carlos, coord., Reseña bíblica, El inmigrante en la Biblia. Navarra: Estella-Verbo Divino. 2005.

Mifsud, Tony «Una espiritualidad desde la fragilidad», Revista Mensaje (2014).

Parmentiers, Élizabeth - Daviau, Pierrette - Savoy, Lauriane, (dir.), Une bible des femmes. Paris: Labor et Fides, 2018.

Wénin, André, L'homme biblique, anthropologie et éthique dans le Premier Testament. Paris: Du Cerf, 1999.

Wigoder, Geoffrey, (Ed.) Dictionnaire encyclopédique du Judaïsme. París: Du Cerf/ Robert Laffont, 1965. 